\title{
COGNITIVE SCIENCE
}

A Multidisciplinary Journal

Cognitive Science 39 (2015) 838-841

Copyright (C) 2014 Cognitive Science Society, Inc. All rights reserved.

ISSN: 0364-0213 print/ 1551-6709 online

DOI: $10.1111 / \operatorname{cogs} .12197$

\section{The Importance of Clarifying Evolutionary Terminology Across Disciplines and in the Classroom: A Reply to Kampourakis}

\author{
Elizabeth A. Ware, ${ }^{\text {a }}$ Susan A. Gelman ${ }^{\text {b }}$ \\ ${ }^{a}$ Psychology Department, Viterbo University \\ ${ }^{\mathrm{b}}$ Department of Psychology, University of Michigan
}

Received 9 July 2014; accepted 4 August 2014

Kampourakis's commentary rightly argues for the importance of interdisciplinary discussion among experts in conceptual development, science education, and the history and philosophy of science. Indeed, we viewed our paper (Ware \& Gelman, 2014) as providing a valuable intersection between conceptual development and science education research, and hope that this exchange will encourage further such cross-discipline conversations.

Kampourakis takes issue with our usage of three terms: "Darwinian," "Lamarckian," and "teleological." We address each of these concerns in turn. First, Kampourakis points out that we incorrectly implied that Darwin attributed evolution to "gene recombination and chance mutations." In fact, although individual variation was a critical element in Darwin's model, he did not accurately postulate the source of this variation or the mechanisms of inheritance. This knowledge did not emerge until later, with advances in fields such as molecular biology and genomics. Our definition of "Darwinian" was more consistent with the so-called modern synthesis of evolution (sometimes also referred to as "neo-Darwinism"), which is grounded in Darwin's core ideas about variation and natural selection, but updated with knowledge from subsequent discoveries, such as Mendelian genetics (Huxley, 1942; Mayr, 1982). We acknowledge this oversight on our part and appreciate the clarification. We are also aware that even this model of evolution is now considered outdated (Gould, 2002); however, more recently discovered mechanisms (e.g., genetic drift) were beyond the scope of our focus on purpose-based inheritance reasoning at the individual-organism level.

Second, Kampourakis points out that our use of "Lamarckian" to refer to so-called soft inheritance (Mayr, 1980) is too restrictive because other biologists, including Darwin

Correspondence should be sent to Elizabeth A. Ware, Psychology Department, Viterbo University, 900 Viterbo Dr., La Crosse, WI 54601. E-mail: eaware@ viterbo.edu 
himself, considered the possibility of the inheritance of acquired traits. (Note, however, that we did state that "other biologists before" Lamarck also believed this to be a key mechanism in evolution [Ware \& Gelman, 2014, p. 198].) Although this is correct, soft inheritance is most commonly associated with Lamarck because this was a critical mechanism in his model (Bowler, 1983; Gould, 2002). Our use of "Lamarckian" (or the also commonly used "Lamarckism") is, therefore, consistent with the conventional use of this term to refer to soft inheritance (Mayr, 1991). In contrast, although Darwin considered the possibility of soft inheritance, this was only one of several mechanisms he considered, and not one that he favored. He relied primarily on hard inheritance mechanisms by the time he wrote The Origin of Species (Mayr, 1982, 1991). Thus, our alleged misuse of this term, we believe, reflects a broader practice in the history of science literature.

Third, Kampourakis suggests that we use "teleological" too loosely when we refer to explanations of inheritance that appeal to the necessity or purpose of a property as the underlying mechanism, thereby making them inconsistent with modern evolutionary reasoning. Kampourakis emphasizes the distinction between design-based teleology (i.e., traits exist because they serve a purpose) and selection-based teleology (i.e., traits exist because they serve a purpose that promotes survival, consequently leading the trait to be selected within a species), only the former of which is inconsistent with evolutionary reasoning. To be clear, our paradigm focused on trait heritability at the individual-organism level, not the species level, and, thus, on design-based teleological reasoning. Moreover, it would have been inaccurate for participants to invoke selection-based teleological explanations in this paradigm. That is, it would be incorrect to assume that individual offspring would inherit a particular trait solely because it had been selected over time within a population as a result of its survival advantages - individual variation would still be possible and the underlying mechanism for inheritance would be genetic material from the parents, not survival advantages per se.

Nevertheless, Kampourakis raises an important point regarding the need to clarify how one uses terms. Our use of the design-based sense of "teleological" stems from its typical usage in the conceptual development literature to refer to explanations for objects and natural phenomena in terms of the purposes that they serve. For example, Kelemen (1999) argues that young children possess a promiscuous teleology, in which they view objects of all sorts as being "made for" particular purposes (e.g., mountains exist for people to climb on them). Thus, "teleological" in this sense refers to future-oriented reasoning in which the current function is thought to have caused an entity's existence or development. The design-based sense is also widely used in the science education research when referring to the types of errors that students make in their evolutionary reasoning (e.g., Jensen \& Finley, 1996; Settlage, 1994; Tamir \& Zohar, 1991) and is often used interchangeably with "need-based" (e.g., explaining that organisms acquire traits because they need them to survive) (e.g., Kelemen \& Rossett, 2009; Nehm \& Ridgway, 2011; Rector, Nehm, \& Pearl, 2012). In contrast, the selection-based sense of "teleology" seems to appear more often in the history or philosophy of science literature (Lennox, 1993; Ruse, 2003; Wright, 1976), where it is often pointed out that it is compatible with natural selection (and was accepted as such by Darwin). 
Perhaps the context in which it is most important (and most challenging) to distinguish between these two senses of "teleology" is science education. The teleological errors that students make typically involve attributing design-based mechanisms to selection, such as failing to consider individual variation as the underlying cause for the emergence of a trait (Bishop \& Anderson, 1990; Ferrari \& Chi, 1998; Tamir \& Zohar, 1991). It has been argued that students' design-based teleological reasoning about evolution stems from a broader design stance in which intentional agency is attributed to the creation and development of both natural and human-made phenomena (Evans, 2000, 2001; Kelemen, 2012). Because of this general tendency, blind processes, such as individual variation in natural selection, are likely to be misunderstood as intentional (Kelemen, Rottman, \& Seston, 2013; see also Lombrozo \& Carey, 2006).

Thus, it is critical that science educators be trained to tease apart intuitive design-based reasoning from mechanistic reasoning that accurately considers causal history. As we suggested in our paper, one effective method may be to draw out students' misconceptions (e.g., design-based teleology) and clearly distinguish them from accurate evolutionary reasoning (see also Kampourakis \& Zogza, 2009; Kelemen, 2012). In distinguishing between design-based and selection-based teleology, it may be particularly important to focus on causal laws, such as that an effect (function) cannot precede its cause (genetic factors leading to the emergence of a trait) (Kampourakis \& Zogza, 2009). However, it may be better to avoid using "teleology" altogether to refer to selection-based processes, as it inadvertently emphasizes function as the driving causal mechanism (Kelemen et al., 2012; Mayr, 1982).

In conclusion, as shown in numerous studies (including our own), evolutionary concepts are notoriously difficult to understand and talk about. The nuances between different theories and concepts are often subtle and easily misunderstood-so much so that even experts, such as biology instructors, use imprecise language and concepts. Moreover, as this exchange illustrates, there are misconceptions and inconsistencies in how these concepts are discussed across disciplines. It is therefore fruitful to have these sorts of exchanges to address disciplinary distinctions and commonalities. Prior research has shown that teaching students about the history of evolutionary theory can facilitate more accurate evolutionary reasoning (Jensen \& Finley, 1995, 1996). We appreciate the history lesson this exchange has prompted for us and hope that it encourages others to be mindful of how research in other disciplines might inform their own thinking.

\section{References}

Bishop, B., \& Anderson, C. A. (1990). Student conceptions of natural selection and its role in evolution. Journal of Research in Science Teaching, 27, 415-427.

Bowler, P. J. (1983). The eclipse of Darwinism: Anti-Darwinian evolution theories in the decades around 1900. Baltimore, MD: The John Hopkins University Press.

Evans, E. M. (2000). The emergence of beliefs about the origins of species in school-age children. MerrillPalmer Quarterly, 46, 221-254. 
Evans, E. M. (2001). Cognitive and contextual factors in the emergence of diverse belief systems: Creation versus evolution. Cognitive Psychology, 42, 217-266.

Ferrari, M., \& Chi, M. T. H. (1998). The nature of naïve explanations of natural selection. International Journal of Science Education, 20(10), 1231-1256.

Gould, S. J. (2002). The structure of evolutionary theory. Cambridge, MA: Harvard University Press.

Huxley, J. (1942). Evolution: The modern synthesis. London: Allen and Unwin.

Jensen, M. S., \& Finley, F. N. (1995). Teaching evolution using historical arguments in a conceptual change strategy. Science Education, 79(2), 147-166.

Jensen, M. S., \& Finley, F. N. (1996). Change in students' understanding of evolution resulting from different curricular and instructional strategies. Journal of Research in Science Teaching, 33(8), 879-900.

Kampourakis, K., \& Zogza, V. (2009). Preliminary evolutionary explanations: A basic framework for conceptual change and explanatory coherence in evolution. Science \& Education, 18, 1313-1340.

Kelemen, D. (1999). The scope of teleological thinking in preschool children. Cognition, 70, 241-272.

Kelemen, D. (2012). Teleological minds: How natural intuitions about agency and purpose influence learning about evolution. In K. S. Rosengren, S. Brem, E. M. Evans, \& G. Sinatra (Eds.), Evolution challenges: Integrating research and practice in teaching and learning about evolution. Oxford, UK: Oxford University Press.

Kelemen, D., \& Rossett, E. (2009). The human function compunction: Teleological explanation in adults. Cognition, 11, 138-143.

Kelemen, D., Rottman, J., \& Seston, R. (2013). Professional physical scientists display tenacious teleological tendencies: Purpose-based reasoning as a cognitive default. Journal Of Experimental Psychology: General, 142(4), 1074-1083. doi:10.1037/a0030399.

Lennox, J. G. (1993). Darwin was a teleologist. Biology and Philosophy, 8, 409-421.

Lombrozo, T., \& Carey, S. (2006). Functional explanation and the function of explanation. Cognition, 99, 167-204.

Mayr, E. (1980). Prologue: Some thoughts on the history of the evolutionary synthesis. In E. Mayr \& W. B. Provine (Eds.), The evolutionary synthesis: Perspectives on the unification of biology (pp. 1-48). Cambridge, MA: Harvard University Press.

Mayr, E. (1982). The growth of biological thought: Diversity, evolution, and inheritance. Cambridge, MA: Harvard University Press.

Mayr, E. (1991). One long argument: Charles Darwin and the genesis of modern evolutionary thought. Cambridge, MA: Harvard University Press.

Nehm, R. H., \& Ridgway, J. (2011). What do experts and novices "see" in evolutionary problems? Evolution Education \& Outreach, 4, 666-679.

Rector, M. A., Nehm, R. H., \& Pearl, D. (2012). Learning the language of evolution: Lexical ambiguity and word meaning in student explanations. Research in Science Education, 43(3), 1107-1133.

Ruse, M. (2003). Darwin and design: Does evolution have a purpose? Cambridge, MA: Harvard University Press.

Settlage, J. (1994). Conceptions of natural selection: A snapshot of the sense-making process. Journal of Research in Science Teaching, 31(5), 449-457.

Tamir, P., \& Zohar, A. (1991). Anthropomorphism and teleology in reasoning about biological phenomena. Science Education, 75, 57-67.

Ware, E. A., \& Gelman, S. A. (2014). You get what you need: An examination of purpose-based inheritance reasoning in undergraduates, preschoolers, and biological experts. Cognitive Science, 38, 197-243.

Wright, L. (1976). Teleological explanations: An etiological analysis of goals and functions. Berkeley, CA: University of California Press. 